Journal of Energy and
Environmental Sustainability
Journal homepage : www.jees.in

\title{
Appraisal of Physicochemical Properties of Castor Oil Biodiesel Blends with Petro-diesel
}

\author{
Chika Muhammad, Muhammad Sabiu Jibrin*, Muhammad Mukhtar, Abdullahi Muhammad \\ Sokoto, Aliyu Sarkin Baki
}

Department of Pure and Applied Chemistry, Usmanu Danfodiyo University, P.M.B. 2346, Sokoto, Nigeria

\section{A R T I C L E I N F O}

Received : 20 April 2018

Revised : 19 June 2018

Accepted : 05 July 2018

Keywords:

Biodiesel, blend, petro diesel, refluxed calcined snail shell, castor seed oil and transesterification.

\begin{abstract}
A B S T R A C T
Addition of additives or blending of conventional diesel with biodiesel improve the cetane number and minimize emission of greenhouse gases. In this study, the biodiesel was produced from refined castor seed oil using refluxed calcined snail shell $(\mathrm{CaO})$ as the catalyst. The refluxed calcined snail shell catalyst was prepared by hydrothermal method. The castor seed oil was extracted by Soxhlet extraction method and the extracted oil has undergone pretreatment i.e. degumming and neutralization, in order to upgrade its physicochemical properties. The biodiesel produced was blended with conventional diesel as B10, B20 and B50 with different proportions. The physicochemical properties of biodiesel, conventional diesel and blends were analyzed and compared with ASTM standards of conventional diesel. The B10 biodiesel has the specific gravity $(0.8586)$, kinematic viscosity $\left(3.50 \mathrm{~mm}^{2} / \mathrm{s}\right)$, cetane number $(51.7702)$ and flash point $\left(69^{\circ} \mathrm{C}\right)$. This implies that the B10 blend has properties that correspond to the ASTM specifications of petrol-diesel; hence it has the potential to be used in the conventional diesel engine without necessary modification.
\end{abstract}

\section{Introduction}

Industrialization, urbanization as well as proportionate growth in the automotive sector has to lead to a remarkable increase in consumption of petrol-diesel (Khachane and Bhuibhar, 2015). These have constantly posed an impact to the deflation of the fossil fuel reserve and corresponding environmental dilapidation. Day after day situation is becoming worse as consumption of petrol-diesel is high and the on going increasing by $2 \%$ each year and attenuation of crude oil reserves (Khachane and Bhuibhar, 2015). In order to seek for redress; several researchers have focused their attention towards searching for sustainable alternative sources of fuels especially for automobile sectors. Anwar et al. (2010) produced biodiesel from okra (Hibiscus esculentus) seed oil. The results of the study showcased that the biodiesel produced had suitable physical and chemical characteristics for general use in combustion engines. Morshed et al. (2011) investigated the potential of rubber seed oil (RSO) to produce biodiesel in Bangladesh, their findings indicated that the rubber produced from RSO had good chemical and physical properties for biodiesel production. Similarly, Qiu et al. (2011) produced a new type of biodiesel using mixed soybean oil and rapeseed oil. The results obtained from their study showed that the properties of the fuel produced, have potential to be used as an alternative to diesel. Lavanya et al. (2012) examined various castor genotypes (Ricinus communis L.) for biodiesel production. In their research, 15 castor genotypes were collected from different regions of India. The chemical and physical structures of the oils obtained from different castor genotypes were compared. The results of the study showed that genotypes 48-1 and DCH-200 had high oil contents, low iodine values (IVs), and high cetane numbers. Nehdi et al. (2012) examined garden cress (Lepidium sativum Linn.) seed oil in terms of the properties required for biodiesel production. The oil content of garden cress seed oil was reported to be $26.77 \%$ and the extracted oil contained $42.23 \%$ polyunsaturated fatty acids and $39.62 \%$ monounsaturated fatty acids. The results of alkali-catalysed transesterification experiments showed that the biodiesel conversion rate is appreciable and has physical and chemical properties within the range of the American Standard for Testing and Materials (ASTM) standards.

Biodiesel emerges as one of the most energy-efficient and environmentally friendly options in recent times to fulfil the future energy needs (Nakarmi and Joshi, 2014; Owolabi et al., 2012). Biodiesel is a renewable diesel substitute that can be obtained by combining chemically any natural oil or fat with alcohol. The biodiesel production has evolved from the lab scale research stage to a large scale pilot production in many developing countries (Zhang et al., 2003). In Nigerian context, nonedible oils are emerging as a preferred feedstock and attempt was made on field trials for the production of biodiesel (Okechukwu et al., 2015; Owolabi et al., 2012).

The physicochemical characteristics of biodiesel are close to diesel fuels and therefore biodiesel becomes a strong alternative to replace the diesel fuels (Atabani et al., 2013). The conversion of triglycerides into methyl or ethyl esters through the transesterification process reduces the molecular weight to one-third that of the triglyceride, reduces the viscosity by a factor of about one-eighth and increases the volatility marginally

\footnotetext{
*Corresponding Author: muhammadsabiu44@gmail.com
} 
(Nakarmi and Joshi, 2014). Biodiesel has a viscosity close to diesel fuels (Demirbas, 2008). These esters contain averagely 10 to $11 \%$ oxygen by weight, which may encourage efficient combustion than hydrocarbonbased diesel fuels in an engine due to inherent oxygen content in biodiesel. Biodiesel has lower volumetric heating values (about 12\%) than diesel fuels but has a high cetane number and flash point (Owolabi et al., 2012).

Zhou, 2013, reported that the biodiesel can be used directly in a diesel engine in its neat pure form called B100 (100\% biodiesel) or in a blend with different proportions of conventional diesel fuels. Common blends include B20 (20\% biodiesel and 80\% conventional diesel), which are much closer to diesel fuel properties than B100 and B5 (5\% biodiesel and $95 \%$ conventional diesel) (Zhou, 2013). Blending of petrodiesel with biodiesel was discovered to have significantly improved the quality i.e. cetane number and reduced emission of greenhouse gasses of the petrodiesel (Sivaramakrishnan and Ravikumar, 2012).

The objectives of this research are to blends biodiesel produced with petro-diesel into B10, B20 and B50 different proportions and compare their physicochemical parameters in order to determine the blend that has similar properties with conventional diesel. The work used novel refluxed calcined snail shell as the catalyst in the production of the biodiesel and method followed for the blending.

\section{Methods}

\subsection{Sampling and Preproduction Process}

The castor seed was procured from Yandodo, Kano State, Nigeria. The seed was sundried to reduce the moisture content. The castor seed was de-shelled. The de-shelled seed was oven dried at $90{ }^{\circ} \mathrm{C}$ for 45 minutes. The dried seeds were ground using mortar and pestle and weighed. Extraction of castor oil was carried out by soxhlet extraction method. The extracted oil was subjected to some pretreatments in order to upgrade it physicochemical properties for better efficiency for transesterification reaction.

The calcium oxide catalyst used in this study was synthesized from snail shell through the hydrothermal method as reported by Ismail et al. (2016).

\subsection{Transesterification of Castor Seed Oil}

The transesterification was carried out in $500 \mathrm{~cm}^{3}$ two necks round bottom flask as reactor equipped with condenser, thermometer and hotplate magnetic stirrer. The $45 \mathrm{~g}$ of refined castor oil was initially charged into the reactor, and then preheated to $50^{\circ} \mathrm{C}$. In order to maintain the catalytic activity, the solution of $0.225 \mathrm{~g}(0.5 \mathrm{wt} \%)$ of $\mathrm{CaO}$ (refluxed calcined snail shell) in $9.169 \mathrm{~g}$ (1:6 oil to methanol ratio) methanol was freshly prepared so that prolonged contact with the air would not diminish the effectiveness of the catalyst through interaction with moisture and carbon dioxide. The solution was preheated to $50{ }^{\circ} \mathrm{C}$ in the water bath and then added to the preheated oil after which the reaction was timed at 1 hour and the agitation was kept at $300 \mathrm{rpm}$. After the reaction time, the mixture was allowed to settle under gravity for 24 hours in the separating funnel. Two distinctive layers were formed: the upper layer consisted of methyl ester, methanol traces, residual catalyst, and other impurities, whereas the lower layer consisted of glycerol, excess methanol, catalyst, and other impurities. After separation from the glycerin layer, the methyl ester layer was centrifuged and then purified by washing with hot distilled water at $60^{\circ} \mathrm{C}$ until the washing water had a $\mathrm{pH}$ value similar to that of distilled water (Nakarmi and Joshi, 2014). The hot distilled water-to-crude methyl ester ratio was $1: 1$. To prevent the possibility of losing the methyl ester due to emulsion formation, the washing was done gently. After then the weight of biodiesel was taken and yield was determined.

\subsection{Biodiesel Blends with Petrodiesel}

The $\mathrm{B}_{10}$ was prepared by heating $90 \mathrm{~cm}^{3}$ of petrodiesel in $250 \mathrm{~cm}^{3}$ beaker at $50{ }^{\circ} \mathrm{C}$ on a hotplate magnetic stirrer agitating at $600 \mathrm{rpm}$. The $10 \mathrm{~cm}^{3}$ of biodiesel was added and allowed under the same conditions for 15 minutes in order to ensure uniformity. The same procedure was adopted in the preparation of $\mathrm{B}_{20}$ and $\mathrm{B}_{50}$ (Sivaramakrishnan and Ravikumar, 2012).

\subsection{Physicochemical Properties of Oil}

The physicochemical properties studies of biodiesel, conventional diesel and blends were carried out based on the method as follows: Cloud, pour and flash point were carried out as reported by Faduka, 2001. The specific gravity, refractive index and kinematic viscosity were conducted based on Akpan et al., 2006 approach. API gravity and Cetane index were determined by the methods ASTM D1250 and ASTM D611, while high heating value was calculated by formula reported by Sivaramakrishnan and Ravikumar, 2012.

\section{Results and Discussion}

Biodiesel is usually added to conventional diesel as an additive in order improved its fuel properties such as cetane number, high heating value, reduce emissions of sulfur oxides $\mathrm{SO}_{x}$, total unburned hydrocarbons, carbon monoxide etc. In this study, the biodiesel blends of B10, B20 and B50 were prepared and their physicochemical properties were studied and presented in Table 1 .

\subsection{Physicochemical Properties of Biodiesel Blends with Conventional Diesel}

\subsubsection{Kinematic Viscosity}

The acceptable range of kinematic viscosity for diesel fuel at $40{ }^{\circ} \mathrm{C}$ is 1.3 to $4.1 \mathrm{~mm}^{2} / \mathrm{s}$ as indicated by ASTM standard. The kinematic viscosity of pure biodiesel (B100) produced was found to be $10.7 \mathrm{~mm}^{2} / \mathrm{s}$ which is above the required range while the conventional diesel (B0) has a kinematic viscosity of $2.80 \mathrm{~mm}^{2} / \mathrm{s}$. The viscosity of B10, B20 and B50 blends of biodiesel with petrodiesel are $3.5,5.45$ and $7.12 \mathrm{~mm}^{2} / \mathrm{s}$ respectively (Fig.1). This indicates that as biodiesel increase in the blends from B10 to B50, kinematic viscosity significantly increases. This collaborates with Goswami and Usmani (2014). A similar value $\left(3.02 \mathrm{~mm}^{2} / \mathrm{s}\right.$ ) for B10 blend was obtained by Goswami and Usmani (2014). The viscosity of biodiesel blend B10 is between 3 and $4 \mathrm{~mm}^{2} / \mathrm{s}$ as indicated in Fig.1. This shows that B10 is highly favourable base on proper ignition due to the lower value of viscosity. And it is may be capable to fulfil the demand of additive fuel by saving diesel and effectively utilize for better performance of diesel engine.

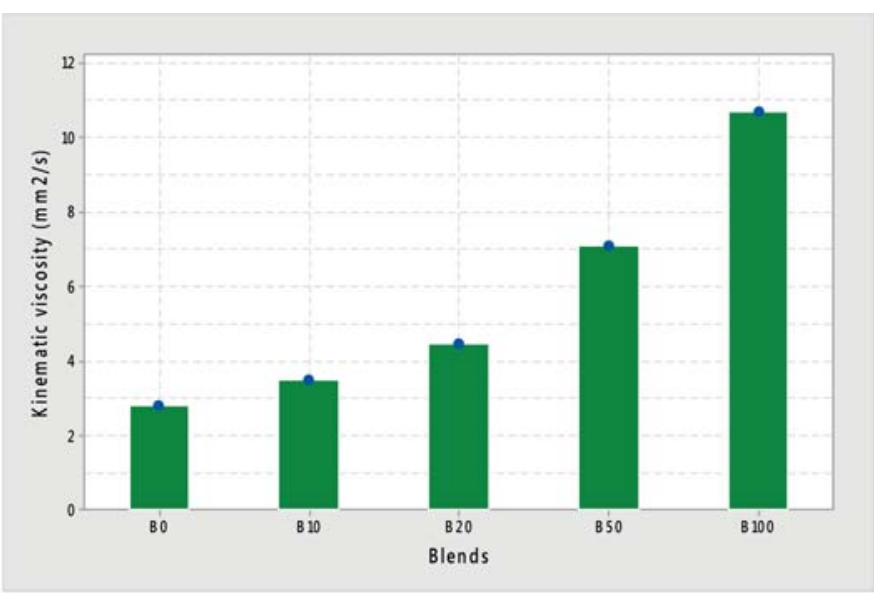

Fig. 1: Interval plot of viscosity versus blends

\subsubsection{High Heating Value}

The high heating value shows the energy content (calorific value) of the fuel. The calorific value of B0 and B100 calculated are 40.745 and 44.339 MJ/Kg respectively. As the conventional fuel blends with biodiesel to produced $\mathrm{B} 10, \mathrm{~B} 20$ and $\mathrm{B} 50$, the high heating value increase to 41.06 , 41.971 and $42.743 \mathrm{MJ} / \mathrm{Kg}$ respectively (Fig.2). This show that as the biodiesel increase in the blend, the gross calorific value of the blend increase which means, the amount of heat released by combusting a specified quantity increase. B50 has satisfied the ASTM standard as indicated in Table 1.

\subsubsection{Cetane Number}

It was observed that the fuel properties of biodiesel play a significant role in the combustion process. One such property is cetane number, $(\mathrm{CN})$ influence the combustion process and engine performance. The $\mathrm{CN}$ is a commonly used as an indicator for the determination of diesel fuel ignition quality. It measures the readiness of the fuel to auto-ignite when injected into the engine (Sivaramakrishnan and Ravikumar, 2012). The cetane number of biodiesel and conventional diesel calculated are 51.4382 and 57.1139. The cetane number of B10, B20 and B50 increases to $51.7702,52.3390$ and 57.1139 respectively as petro-diesel was blended with biodiesel accordingly (as indicated in Fig.2). This indicates that the blends will have superior ignition quality compare to conventional diesel. 
Table 1: Properties of Biodiesel blends with petrodiesel, and ASTM limits for diesel and biodiesel fuels

\begin{tabular}{l|c|r|r|r|r|r|r|r|r}
\hline \multicolumn{1}{c|}{ Parameter } & Unit & \multicolumn{1}{c|}{$\mathrm{B}_{0}$} & \multicolumn{1}{c|}{$\mathrm{B}_{10}$} & \multicolumn{1}{c|}{$\mathrm{B}_{20}$} & \multicolumn{1}{c|}{$\mathrm{B}_{50}$} & \multicolumn{1}{c|}{$\mathrm{B}_{100}$} & Method ASTM & Biodiesel limit & Diesel limit \\
\hline Viscosity @ $40{ }^{\circ} \mathrm{C}$ & $\mathrm{mm}^{2} / \mathrm{s}$ & 2.8000 & 3.5000 & 4.4500 & 7.1200 & 10.7000 & $\mathrm{D} 445$ & $1.9-6.0$ & $1.3-4.1$ \\
Specific gravity & - & 0.8526 & 0.8586 & 0.8598 & 0.8894 & 0.9246 & $\mathrm{D} 6751$ & $0.86-0.90$ & $0.82-0.88$ \\
API gravity & - & 34.4629 & 33.3032 & 33.0732 & 27.5960 & 21.5392 & $\mathrm{D} 287$ & - & $-30-42$ \\
Cloud point & ${ }^{\circ} \mathrm{C}$ & 5.2000 & 4.1000 & 3.6000 & 3.3000 & 2.8000 & $\mathrm{D} 2500$ & -3 to 12 & -15 to 5 \\
Pour point & ${ }^{\circ} \mathrm{C}$ & 15.9000 & -14.8000 & -14.1000 & -13.6000 & -10.8000 & $\mathrm{D} 97$ & -15 to 10 & -25 to -15 \\
High heating value & $\mathrm{MJ} / \mathrm{Kg}$ & 40.7450 & 41.0690 & 41.9710 & 42.7430 & 44.3990 & $\mathrm{D} 21663$ & - & $42.80-45.36$ \\
Cetane index & - & 57.5530 & 58.0142 & 58.8041 & 60.9872 & 65.4361 & - & - \\
Cetane number & - & 51.4382 & 51.7702 & 52.3390 & 53.9108 & 57.1139 & $\mathrm{D} 6751$ & $48-65$ & $40-55$ \\
Flash point & ${ }^{\circ} \mathrm{C}$ & 60.0000 & 69.0000 & 98.0000 & 132.0000 & 171.0000 & $\mathrm{D} 93$ & $100-170$ & $60-80$ \\
\hline
\end{tabular}

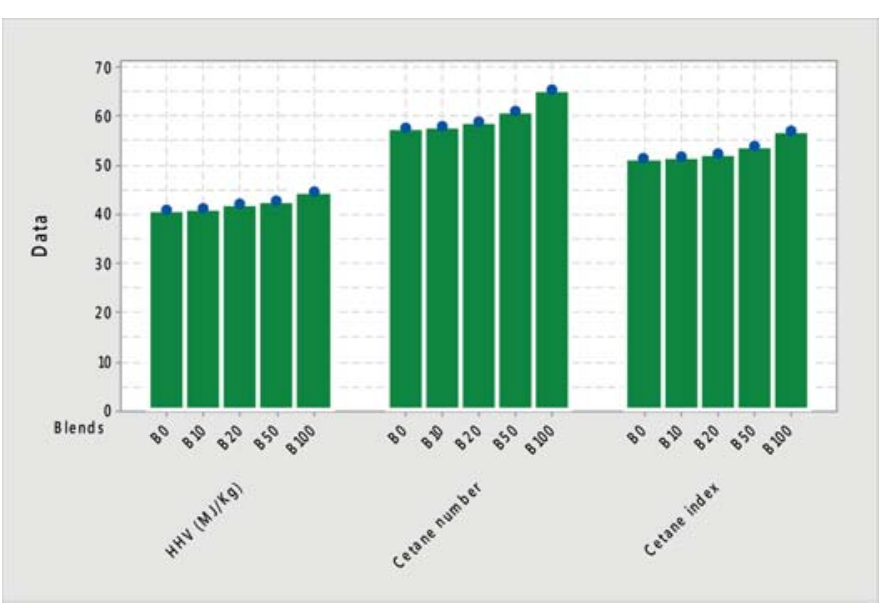

Fig. 2: chart of HHV, cetane number and cetane index

\subsubsection{Cetane Index}

Diesel index is an indicator of the good ignition quality of diesel fuel. As the cetane index increases the diesel fuel ignition quality will be improved (Goswami and Usmani, 2014). The conventional diesel was determined to have cetane index of 57.5530. As it was blended with biodiesel the cetane index significantly increases as indicated in the Fig.2, this collaborated with Goswami and Usmani (2014). The cetane index of B10, B20, B50 and B100 are 58.0142, 58.8041, 60.9872 and 65.4361 respectively. This shows that there is a weighty improvement in the combustion and diesel engine performance when petrol-diesel blends with biodiesel.

\subsubsection{Specific Gravity and API Gravity}

The specific gravity of the conventional diesel as specified by ASTM standards are in the range of 0.82- 0.88 . API gravity was calculated from the specific gravity. The higher the specific gravity of the fuel, the lower the API gravity. The specific gravity and API gravity of the petrodiesel as presented in Table 3.12 are 0.8526 and 34.4629 , while for the biodiesel are 0.9246 and 21.5392 respectively. This indicates that specific gravity/ API gravity of the biodiesel is out of the ASTM standard for petrodiesel and it dangerous to be used in petrodiesel engine. But as the petrodiesel was blended with biodiesel as in B10, B20 and B50, the specific gravity/ API gravity changed to $0.8586 / 33.3032,0.8598 / 33.0732$ and $0.8894 /$ 27.5960 respectively (Fig. 3.). This indicates that blends B10 and B20 are within the ASTM standards of conventional diesel and maybe use amicably on the petrodiesel engine based on their specific/API gravity aspects.

\subsubsection{Flash Point}

As indicated in the Fig. 3, as the quantity of biodiesel increases in the blends, the flashpoint significantly increases. This indicates that the volatility of the blends decreases with increase in biodiesel. The ASTM standards of the flash point of the conventional diesel as presented in Table 1 is in the range of $60-80^{\circ} \mathrm{C}$, this show that only blend $\mathrm{B} 10$ satisfied the specification, hence, it may be used directly in the conventional diesel engine without modification base on flashpoint aspect.

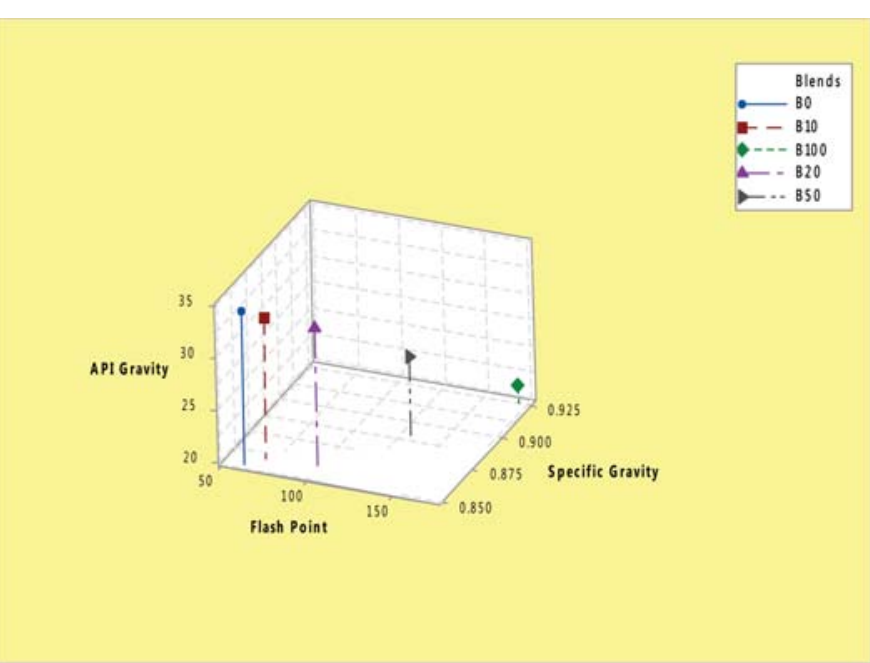

Fig. 3: 3D scatter plot of specific gravity, flash point and API gravity

\subsubsection{Cloud Point and Pour Point}

Pour point is the lowest temperature at which it has utility in a certain application. While, the cloud point is the temperature at which the dissolved materials are no longer soluble in the oil and precipitated, which will give oil cloudy appearance. After the cloud point, the next stage is the pour point. ASTM Specification for maximum pour point and cloud point of conventional diesel as presented in Table 1 are ranged -25 to $-15^{\circ} \mathrm{C}$ and -15 to $5{ }^{\circ} \mathrm{C}$. The market purchased diesel has a pour and cloud point of -15.9 and $5.2{ }^{\circ} \mathrm{C}$. All the blends B10, B20, B50 and Biodiesel B100 fall within the ASTM standard range of required cloud point of petrol-diesel but only B10 blend closely satisfied the ASTM specification of the pour point. So under very low temperature, where petrodiesel can be used, B10 can also work based on it a related value of pour point. Thus increasing amount of biodiesel decreases the pour point of biodiesel and this observation is corroborated by Goswami and Usmani (2014).

\section{Conclusions}

The physicochemical properties of prepared blends B10, B20 and $\mathrm{B} 50$, shows that the kinematic viscosity, high heating value, cetane number, specific gravity, cetane index and flash point increase with an increase in biodiesel in the blend while, API gravity and cloud point decrease with increase in biodiesel in the blend. The physicochemical properties of blends were compared with ASTM standard in order to find the blends that have the potential to be used directly in the diesel engine. B10 have satisfied all the specification of ASTM standards of conventional diesel, therefore, it has the potential to be used on conventional diesel engine without necessary modifications of the engine, and hence, engine test is recommended.

\section{Acknowledgements}

One of the authors, Muhammad Sabiu Jibrin (PTDF/ED/LSS/MSC/ MSJ/389/17), acknowledged the Petroleum Technology Development Fund (PTDF) for sponsoring this research work. 


\section{References}

Akpan, U. G., Jimoh, A. and Mohammed, A. D. (2006). Extraction, Characterization and Modification of Castor Seed Oil. Leonardo Journal of Sciences, 8: 43-52.

Anwar F, Rashid., U., Ashraf, M. and Nadeem, M.(2010) Okra (Hibiscus esculentus) seed oil for biodiesel production. Applied Energy, 87(3):779 - 85.

Atabani, A. E., Silitonga, A. S., Badruddin, I. A., Malilia, T. M. I., Masjuki, H. H. and Mekhiled, S. A.(2012). Comprehensive Review on Biodiesel as an Alternative Energy Resource and its Characteristics. Renewable and Sustainable Energy Reviews; 16(4): 2070-2093.

Demirbas, A. (2008). Biofuels Sources, Biofuel Policy, Biofuel Economy and Global Biofuel Projections. Energy conversion and management, 49(8): 2106-2116.

Fuduka, H., Kando, A. and Noda, H., (2001).Biodiesel Fuel Production by Transesterification of Oils. Journal of Bioscience and Bioengineering, 92: 405415.

Goswani, A. K. and Usmani, G. A. (2014). Characterization of Biodiesel Obtained from Pure Soybeans Oil and its various Blends with Petrodiesel. International Journal of Innovative Research in Science, Engineering and Technology, 3(9): 2319- 8753.

Ismail, S., Ahmad, A. S., Anr, R. and Hamdan, S. (2016). Biodiesel Production from Castor Oil by Using Calcium Oxide Derived from Mud Clam Shell. Journal of Renewable Energy, 2016: 5274917, http://dx.doi.org/10.1155/2016/5274917, 12/03/ 2017 at 02:45 pm.

Khachane, V. S. and Bhuibhar, A. G. (2015). Performance of Diesel Engine with Different Biodiesel Blends of Castor Oil, a Review. International Research Journal of Engineering and Technology. 2: 1967:1976.

Lavanya, C., Murthy, I. Y. L. N., Nagaraj, G., Mukta, N. (2012) Prospects of castor (Ricinus communis L.) genotypes for biodiesel production in India. Biomass Bioenergy, 39:204-9.
Morshed M, Ferdous, K., Khan, M.R., Mazumder M.S.I., Islam, M.A. and Uddin MDT., (2011). Rubber seed oil as a potential source for biodiesel production in Bangladesh. Fuel, 90(10):2981-6.

Nakarmi, A. and Joshi, S. (2014). A study on Castor Oil and its Conversion into Biodiese by Transesterification Method. Nepal Journal of Science and Technology, 15(1): 45-52.

Ndana, M., Garba, B., Hassan, L. G., and Faruk, U. Z. (2011). Evaluation of Physicochemica Properties of Biodiesel Produced from Some Vegetable Oils in Nigerian Origin. Bayero Journal of Pure and Applied Sciences, 4(1): 67-71.

Nehdi, IA, Sbihi, H., Tan, C.P, Al-Resayes, S. (2012). Garden cress (Lepidium sativum Linn.) seed oil as a potential feedstock for biodiesel production. Bioresource Technology, 126:193-7.

Okechukwu, R. I., Iwuchukwu A. C. and Anuforo, H. U. (2015). Production of Biodiesel from Ricinus Communis Seeds. Research Journal of Chemical Sciences, 5(2): 1-3, ISSN 2231 -606X.

Owolabi, R. U., Adejumo, A. L. and Aderibigbe, A. F. (2012). Biodiesel: Fuel for the Future. International Journal of Energy Engineering, 2(5): 223-231.

Qiu F, Li, Y., Yang. D., Li, Y., and Sun, P. (2011). Biodiesel production from mixed soybean oil and rapeseed oil. Applied Energy, 88(6):2050-5.

Sivaramakrishnan, K. and Ravikumar, P. (2012). Determination of Cetane Number of Biodiesel and Its Influence on Physical Properties. ARPN Journal of Engineering and Applied Sciences, 2(2): ISSN 1819- 6608.

Zhang, Y., Dube, M. A., McLean, D. D. and Kates, M. (2003). Biodiesel Production from Waste Cooking oil: 1. Process Design and Technological Assessment. Bioresource Technology, 90: 1-16.

Zhou, L.. (2013). Reaction Kinetics of Biodiesel Production by Using Low-Quality Feedstock. Thesis Submitted to Faculty of Graduate Studies and Research, Environmental System Engineering, University of Regina, 25- 60. 